\title{
The Implicit-Explicit Dichotomy in Language Teaching/Learning: A Proposal for an Update
}

\author{
Paula Garcia de Freitas ${ }^{1}$ \\ Federal University of Paraná \\ Rua General Carneiro, 460, $9^{\circ}$ andar, CEP 80.060-150 \\ Curitiba, Paraná, Brazil \\ Graziele Altino Frangiotti ${ }^{2}$ \\ University of São Paulo \\ Av. Professor Luciano Gualberto, 403 - Prédio de Letras, $2^{\circ}$ Andar, CEP 05508-010, \\ São Paulo, Brazil
}

\begin{abstract}
The division of linguistic phenomena into two-sided subsets, i.e., dichotomies, has strongly influenced discussions in the field of linguistics. While dichotomies benefit the dialogue within this field, they sometimes seem to represent a kind of limitation to the researcher, who is forced to reduce linguistic complexity to monolithic parameters. This also appears to be the case of the implicit-explicit dichotomy in the field of language teaching/learning, in which different didactic techniques necessarily must be classified either as implicit or as explicit, as if there were no alternative path. The objective of the present article is to discuss this issue and to bring forward a perspective that sees dichotomies as extremes of a continuum that enables different degrees of intermediate explanation.
\end{abstract}

Keywords: Dichotomies in linguistics; Language teaching; Language learning; Implicit and explicit instruction; Implicit and explicit techniques; Continuum.

\section{Introduction}

The birth of modern linguistics is deeply marked by the impact of postulates that have grounded a new conception of language as a system and language as a phenomenon and charted new scientific paths for the discipline. In his Course of General Linguistics, Ferdinand Saussure (1916) grounds the main points of his theory on thoughts built from dichotomies.

The word dichotomy is Greek in origin and means "divided in two". Thus, the Saussurean dichotomies establish separations of a whole into two fundamental parts. The concepts of language and speech, diachrony and synchrony, syntagma and paradigm, and signifier and signified organize language as a set of values that oppose and exclude each other. Under this perspective, language studies are either diachronic or synchronic; language elements are situated either on the syntagmatic or paradigmatic axis; an aspect of the linguistic sign belongs either to its signifier or to its signified. Therefore, according to Saussurean theory, there is no room for intermediate elements; everything must belong to one term or another of the bipartition so that no part of one term is included in the other.

Throughout the 20th century, several other dichotomies were conceptualized - such as Noam Chomsky's competence and performance and Dell Hymes' linguistic competence and sociolinguistic competence - in addition to the many debates based on great antagonistic theories - such as innatism versus environmental learning, functionalism versus formalism, among others.

Along with this trend, the area of language teaching/learning is also profoundly influenced by concepts structured from binomials. Stephen Krashen $(1982,1985)$, for example, opposes language acquisition to language learning. Krashen defines acquisition as a subconscious process, in which those who acquire a second language (L2) are not aware of the fact that they are acquiring it, but only that they are using it to communicate. Learning, on the other hand, comprises a conscious knowledge on the part of the learner, who becomes able to talk about the language. In other words, either the individual acquires a language without realizing it, that is, in a natural way, or he learns its functioning and its rules, being aware of the learning process.

\footnotetext{
${ }^{1}$ Ph.D. in Linguistics from the Federal University of Santa Catarina, Brazil. Professor at the Undergraduate Program in Italian Education of the Federal University of Paraná (UFPR). Coordinator and designer teacher training projects for different levels and contexts, like IsF-Italiano (UFPR) and Licenciar-Italiano (UFPR). E-mail: paulag_freitas@ufpr.br. ${ }^{2} \mathrm{Ph} . \mathrm{D}$. in Letters from the University of São Paulo in Brazil. Develops research in the area of teaching Italian as a foreign language, Applied Linguistics and Corpus Linguistics. Participates in Italian teacher training projects and develops and teaches language courses for different levels and contexts in the public and private sphere. E-mail: grazielefrangiotti@gmail.com.
} 
Although dichotomies such as those discussed above are recurrent and fundamental to the growth and development of language, we believe that the linguistic phenomenon is extraordinarily complex and that often the adoption of opposed views ends up excluding relevant aspects that do not fit in either extreme.

With this in mind, we propose an analysis of another typical division in language teaching/learning: implicit and explicit instruction. We discuss this topic in order to introduce an update where we expand this dichotomy into a continuum - a fluid concept that is more coherent with our idea of language teaching/learning.

To this end, we draw inspiration from Bortoni-Ricardo (2004), who studied teaching with a focus on linguistic variation, and in her work, proposes that continuums should replace the traditional dichotomies in conventional theoretical models.

As she makes clear in her work, the author adopts this strategy to eliminate the impression that there would be rigid boundaries between the language varieties that make up Brazilian Portuguese. Thus, instead of merely opposing formal register to informal register, for example, Bortoni-Ricardo applies the concept of "stylistic monitoring continuum", in which these concepts encompass from totally spontaneous interactions (minimum degree of monitoring) to previously planned interactions (maximum degree of monitoring), considering a whole range of interactions between one end and the other along a continuum.

Another work which underlies our reflections on the idea of continuum is Doughty and Williams (1998) from the field of Applied Linguistics, who discussed pedagogical strategies to encourage Focus on Form (LONG; ROBINSON, 1998), i.e., ways of inducing the learner's attention to some aspect which was repeated, frequent or prominent in the input, in a communicative context of foreign language (FL) or L2. For the authors, "exercises" and "communicative tasks" could be considered as the two extremes of a continuum of teaching techniques, the exercise being a specific technique, which would lead the learner to train the use of the language form being taught deliberately. The objective of this type of activity is to direct the learner's attention to a specific grammatical aspect. At the opposite end of the spectrum lies the communicative task. This implicit technique would foster the conscious perception of the learner (noticing) through mechanisms that seek to attract the learner's attention to form, avoiding metalinguistic discussions, and minimizing any interruption in communication.

Based on these examples, in this theoretical study, we attempt to demonstrate that the notions of implicit and explicit instruction also do not have precise limits, which causes a series of didactic techniques to be left out of this classification, being linked either to implicit perspective or explicit instruction.

This vagueness causes inaccuracies and confusion in theoretical and empirical research, compromising the objectivity required in scientific studies.

In this section, the present article introduced some questions regarding dichotomies in the field of linguistics and our concern about the implicit-explicit dichotomy in the field of language teaching/learning. Then, we present our proposal for a literature review based on the hypothesis that this monolithic perspective can be expanded upon through the concept of continuum. In the following section, we address the idea of instruction. Then, in section 2, we cite several studies that focus on this concept in an attempt to classify it as explicit or implicit. Taking these studies into consideration, in section 3, we conclude that the different points of view generate inaccuracies and gaps, which can be minimized if we adopt the idea of continuum. To this end, based on the instances Ellis (1998) deems as instruction and on techniques for language teaching described by several authors, we seek to situate these concepts along four continua, and thus advance an update of the concept.

\section{The concept of instruction}

In Applied Linguistics, the term "instruction" indicates the pedagogical choices that teachers must make to organize, design, and analyze a class, teaching material, or activity whose objective is to promote learning by the learner. In our understanding, instruction constitutes "any systematic attempt to enable or facilitate language learning by manipulating the mechanisms of learning or the conditions under which these occur" (HOUSEN; PIERRARD, 2005, p. 02).

Ellis (2009) hypothesizes instruction as an attempt to act on the learner's interlanguage, seeking to attract their attention directly or indirectly on some aspect of the language. ${ }^{3}$

\footnotetext{
${ }^{3}$ The idea of a "direct" and "indirect" form of attention is based on the explicit-implicit dichotomy, in that the direct form would correspond to pedagogical choices that incite metalinguistic knowledge ABOUT the language, while the indirect form would involve strategies that help learners to perceive a certain rule through, for example, its salience and frequency in the text. As such, the latter would generate as a result a verifiable knowledge of the language in the learner's use in a communication context.
} 
Studies carried out in Brazil and abroad (FRANGIOTTI, 2019; FREITAS, 2014; ANDREWS, 2007, NORRIS; ORTEGA, 2000; BONGAERTS, 1999; VANPATTEN; OIKKENON, 1996) seem to indicate that pedagogical intervention does play an essential role in the process of FL learning.

According to Housen and Pierrard (2005), studies show that instruction can positively influence the pace and final stage of learning, but that it is unable to alter the path of acquisition. Thus, learners who receive instruction may be able to progress quicker and even reach higher levels of proficiency than those who learn the language in a spontaneous context. According to these studies, they all must go through the same stages, respecting the same sequences of acquisition, which suggests that instruction is a useful resource to catalyze learning. However, instruction is not a sufficient factor for the learner to skip stages.

Housen and Pierrard (2005) claim that if instruction influences the learning process, its degree of effectiveness would be closely related to three sets of factors: what is taught, who is taught, and how instruction occurs.

The authors state that some contents seem to be more "teachable" than others, beginning with an analysis of the influence caused by what is taught through instruction. "Teachable" content refers to mainly recurrent and salient aspects taught in the input, which is, in language learning, a structure of the target language that appears repeatedly, either in the teacher's speech or in the teaching material that can attract the learner's attention and interest. This would, in turn, facilitate instruction not only because the learner will be more motivated to pay attention to it, but also because he will have already created a certain familiarity with the aspect, simplifying the process of understanding.

Another determining factor is the transparency of the object taught; the closer to the learner's first language (L1) and the simpler the rule underlying the phenomenon, the easier it is for the teacher to explain it, and for the learner to understand it.

On the other hand, some characteristics can make some contents of the target language challenging to instruct. The main one would be complexity. In this sense, according to Harley (1993), complex forms would be those that: a) are different from the structures present in the learner's L1; b) are not prominent in the input; c) are not crucial to successful communication; and d) are poorly understood or poorly analyzed by learners.

Moreover, to whom the instruction is directed as a determining factor for the success of the instruction. This way, we face one of the most complex sets of variables, directly related to the profile of the learner and diverse aspects such as age, level of proficiency in the target language, gender, profession, interests, strategies and learning styles, personal motivation, personality, attitudes towards the FL, cognitive maturity, among others. All these factors are inherent to any classroom, which inevitably interferes with the level of success of instruction, which cannot be controlled by the teacher.

Finally, when we deal with how to carry out the instruction, we reach a crucial point in the teaching process because taking into account all of the aspects cited above, the teacher needs to decide which of the different perspectives of instruction to adopt. There is a whole spectrum of options to solve this issue, from more general alternatives, such as the adoption of teaching methods like the Grammar-Translation Method, the Direct Method, and the Audiolingual Method, to the application of more specific techniques, such as cloze exercises, communicative activities such as roleplays, translation of texts from the FL to the L1, correction through requests for rephrasing, among many others.

Behind the concept that it is possible to make the learner improve his knowledge through instruction, there is the idea that instruction incites this learner to begin to perceive elements in the input, which, without the instruction, would go unnoticed. However, there is an evident disparity between the moment that the teacher provides information about the language and the moment that the learner consolidates this information into output. Therefore, we cannot say that the instruction activates an automatic mechanism that transforms everything the teacher says into knowledge and immediately becomes part of the learner's active repertoire. Based on this, we start from the assumption that not everything the teacher addresses in the classroom is noticed and understood by the learner, just as he or she may learn aspects that have not been explained by the teacher.

In light of the range of available options and the numerous choices the teacher can make, in the next section we will address how research developed inside and outside Brazil has operationalized the opposition between implicit and explicit instruction, so that we can identify the effects of adopting this dichotomy for the field of language studies.

\section{The perspective of implicit and explicit instruction in previous researches}

There are a large number of variables involved in teaching a language, maternal or not. Therefore, it is easy to understand that scholars who dedicate themselves to this subject might not have the same conclusion about this process, nor will they all operate their research methodology in the same way. To picture practical examples of these divergences, we will focus below on demonstrating how this has been happening in studies aimed at investigating the effects of implicit and explicit instruction in the field of FL/L2 teaching/learning. 
Catherine Doughty and Jessica Williams (1998, p. 257-258), for example, consider that the primary purpose of instruction is to teach language for communication and discuss different ways of bringing learners closer to language structures that they might struggle with. In this sense, according to the authors, the pedagogical choices either implicit or explicit - of the FL teacher will depend on some factors (Table 1).

\title{
Table 1: Factors that influence the form-focused instruction
}

\begin{abstract}
a) Learner's attention: "more" explicit activities are those that directs the learner's attention to the form and "more" implicit activities are those that attract the learner's attention to a certain structure;

b) Learner involvement: activities that ask for learners to manipulate form, such as gap-filling exercises, are among the "most" explicit activities, while those that focus on language use without much teacher intervention would be among the "most" implicit activities.

c) Learning conditions: if the learning conditions require deductive teaching, that is, if the aim is to deliberately present the form, this teaching is "more" explicit. On the other hand, if the objective is to encourage the use of the language in real communication situations, the activities can be interpreted as "more" implicit.

d) Integration: if a sequence of activities is envisioned for isolated practice in a given way, they can be considered "more" explicit; on the other hand, if this form is presented to the learner in a communicative context, the form is likely integrated to this communicative activity and therefore it is a "more" implicit activity.

e) Inclusion of metalinguistic information: when the activity proposes the presentation or systematization of the content through metalanguage, it can be said that it is a "more" explicit activity, while activities that do not foresee the description of a rule would be aligned with a "more" implicit perspective.

f) Modes: involves the way a given structure will appear along the activity; whether in the input, during understanding activities, in the output, during production activities, or both.

g) Providers: refers to who is providing the input with the target structure; whether it is the teacher, the material or the learners themselves. When the teacher or the teaching material is the main agent, then instruction is "more" explicit; when, on the other hand, learners can test their hypotheses, interact with each other, with the teacher or even with the teaching material, then instruction is "more" implicit.
\end{abstract}

Source: The authors, based on Table 4 by Doughty and Williams, 1998, p. 258.

Although "learner attention" is mentioned in the first item, the other criteria are more directly associated with the teacher's action and, specifically, the type of activity he will pose to the class. Thus, these criteria form the basis of explicit instruction, that is, activities that direct the learner's attention to FL/L2 structures, involve the teacher's intervention, require the learner to manipulate forms, deliberately present the form in a deductive manner, and provide for metalinguistic treatment. Meanwhile, implicit instruction refers to activities that attract the learner's attention to structures, do not involve the teacher's intervention, do not metalinguistically guide the learner, and focus on the receptive and productive use of the language.

Thus, Doughty and Williams (1998) link the implicit-explicit dichotomy almost exclusively to the act of teaching. Similarly, Housen and Pierrard (2005) also contribute to the discussion through the following table:

Table 2: Differences between explicit and implicit instruction

\begin{tabular}{|l|l|}
\hline Explicit form-focused instruction & Implicit form-focused instruction \\
\hline Directs attention to target forms & Attracts attention to target form \\
\hline $\begin{array}{l}\text { Is predetermined and planned (e.g. as the main focus } \\
\text { and goal of a teaching activity) }\end{array}$ & $\begin{array}{l}\text { Is delivered spontaneously (e.g. in an otherwise } \\
\text { communication-oriented activity) }\end{array}$ \\
\hline $\begin{array}{l}\text { Is obtrusive (interruption of communication of } \\
\text { meaning) }\end{array}$ & $\begin{array}{l}\text { Is unobtrusive (minimal interruption of communication } \\
\text { of meaning) }\end{array}$ \\
\hline Presents target forms in isolation & Presents the target forms in context \\
\hline Uses metalinguistic terminology (e.g. rule explanation) & Makes no use of metalanguage \\
\hline Involves controlled practice of target forms & Encourages free use of target forms \\
\hline
\end{tabular}

Source: Housen and Pierrard, 2005, p. 10 
The number and typology of criteria capable of operating the distinction between explicit and implicit instruction in this model are similar to Doughty and Williams' (1998). However, in their study, the authors emphasize the predetermined and invasive character of explicit instruction.

On the one hand, in implicit instruction, there is no interruption in the flow of communication to explain the rules through metalanguage, the forms are presented spontaneously only through target language samples, and the production of the learners is free, i.e. there are no practice exercises on a given grammatical point. On the other hand, in the explicit perspective, the teacher plans the teaching objects in advance, interrupts the communicationfocused activities to isolate the grammatical aspect and explain the rules underlying it through metalanguage, and proposes exercises to consolidate the forms in question.

In the opposite direction, Ellis (2009) understands the dichotomy as follows:

Implicit instruction is directed at enabling learners to infer rules without awareness. That is, it seeks to provide learners with experience of specific examples of a rule or pattern while they are not attempting to learn it (i.e. they are focused instead on meaning). As a result, they internalize the underlying rule/pattern without their attention being explicitly focused on it. [...] Explicit instruction involves 'some sort of rule being thought about during the learning process' (DeKeyser, 1995). In other words, learners are encouraged to develop metalinguistic awareness of the rule. (ELLIS, 2009, p. 16-17)

From this definition, there is a significant change to the classification criteria proposed in the two previous models. As we can see, the adjectives "explicit" and "implicit" are used in this passage, taking as a reference the learner and his degree of awareness of rules and structural patterns of the target language. Thus, if learners do not consciously reflect on the rules they are learning, it constitutes implicit instruction; if instead, they are encouraged to think about the rules of the target language, then it is explicit instruction. The figure of the learner and the degree of consciousness improve to the detriment of the role of the teacher and the type of activity he develops.

Spada (2011) follows the definitions provided by Norris and Ortega (2000) and differentiates these two types of instruction in the following manner:

Instruction was considered [by Norris and Ortega, 2000] to be explicit if it included rule explanations, and the learners' attention was mainly on forms. Instruction was coded as implicit if there was no rule explanation or if learners were not asked to directly draw their attention to forms. (SPADA, 2011, p. 231).

Notably, while Ellis places learners' awareness of language forms as a determining factor in differentiating the dichotomy, and Doughty and Williams (1998) and Housen and Pierrard (2005) place the teacher's pedagogical choices at the heart of the classification, Spada (2011) merges these two sides, placing the explanation of the rules an example of teaching activity - alongside the learners' attention, giving equal weight to these two factors.

These examples demonstrate that the area of language teaching/learning does not have one single understanding of what is implicit and explicit instruction. The learner's attention is now the primary criterion (ELLIS, 2009; DEKEYSER, 2003; VANPATTEN, 1996; SCHMIDT, 1990), and the teacher's activity is now more critical (FRANGIOTTI, 2019); ANDREWS, 2007; DOUGHY; WILLIAMS, 1998; HOUSEN; PIERRARD, 2005); sometimes the factors taken into consideration are put on the same level (FREITAS, 2014; SPADA, 2011).

On the contrary of this plurality of voices and ideas, however, some studies do not define what they mean by the terms "implicit" and "explicit", taking them as if they were uncontroversial and absolute concepts. This seems to be the case Saugera (2011), Moskver (2008), and Lyster (1994), where the authors only reported that the studies focus on implicit or explicit instruction, without further specification of how these concepts are interpreted, as if they were evident to the reader, which, as evidenced above, is not necessarily true.

In our opinion, precisely because of the variation in the interpretation of these concepts, this last option should be avoided in scientific studies, since readers, familiar or not with this terminology, are unable to achieve a more effective understanding of the methodological design of the research and, consequently, of the results and conclusions obtained. The absence of an unambiguous definition of how the dichotomy was put into practice creates a gap that could compromise the transparency and reliability of research.

As discussed in this section, although the dichotomy of explicit and implicit instruction is very recurrent in the literature in the teaching/learning languages field, it has no accurate definition. In light of this, we propose a way to apply this dichotomy for its potential users to have more resources to classify more precisely the techniques they choose to employ in their research or the classroom.

\section{The implicit and explicit instruction: update proposal}

To advance our update proposal, we draw from Ellis (1998, p. 42-43), according to whom classroom instruction can intervene in four points of the development of interlanguage: 
1. when instruction is directed at input; 2. in the explicit treatment of the functioning of linguistic forms; 3 . in the production practice; and 4 . in the correction of these productions.

Like Ellis, we understand that instruction is not restricted only to the classroom, in which the teacher addresses the blackboard and dwells on the explanation of language phenomena and rules.

We believe instruction also takes place through the texts brought to class by the teacher, by offering opportunities for meaningful interaction and providing corrective feedback, since these are all mechanisms designed by the teacher to allow or facilitate the learning process.

According to the terminology proposed by Ellis (1998), input-based instruction is called structured input. According to this type of instruction, authentic oral and written texts are handled in advance by the teacher in such a way as to encourage learners to notice language structures while they are involved in understanding their meaning.

In an article published in 2007, Vidal builds on Ellis' text and develops a set of techniques to promote structured input. The first is called input enrichment, and the second is input processing.

Input enrichment techniques refer to the manipulation of texts with which learners come into contact in class with the exact aim of "enriching" them in order to make the target grammatical aspects of instruction more evident to the learners' eyes. Two techniques are mentioned in this sense: input enhancement and input flood.

Input enhancement consists of editing parts of the written texts selected by the teacher. Thus, examples of grammatical and lexical structures can be purposefully underlined, put in italics, or have their font colors altered to draw the learners' attention. This technique, of course, is more easily adopted in contexts where learners work on written texts. In working with oral texts, to highlight parts of the spoken language, the teacher can make use of the change in tone of speech when pronouncing certain aspects, placing purposeful emphasis on target forms.

Input flood, on the other hand, refers to texts, usually constructed or manipulated in advance, which contain many examples of grammatical form focused on instruction. With this technique, the high frequency of occurrence of the target structure would constitute an important resource for the increase of the salience of form, favoring its perception.

Input processing can be described as follows: first, the teacher gives a brief linguistic/grammatical introduction of the target structure and then informs learners about how specific input processing strategies tend to negatively affect their understanding of oral or written FL/L2 texts. Finally, activities are proposed so that learners can relate form and meaning in a communicative context (Cf. VANPATTEN, 2002; NEUPANE, 2009). In this type of instruction proposed by VanPatten $(1996,2002)$, learners are invited to read or listen to texts in the target language to process form and meaning and thus show their understanding of the input.

The structures subject to this type of approach are those that (a) differ considerably from the learner's L1 and (b) are likely to be "ignored" when the learner reads or hears texts in FL/L2, such as grammatical items with little communicative value, such as prepositions, articles, and adjectives, which have little semantic content in speech (VANPATTEN, 1996, 2002). Thus, according to VanPatten $(1996,2002)$, there is a need for more explicit teaching.

Wong (2004), following the theories of VanPatten, proposes that input processing should first consider oral and written input; also, one thing should be presented at a time, keeping the focus on meaning. The teacher should lead learners to do something with the input, for example, to say whether or not they agree with the ideas conveyed.

Although Wong (2004) does not specify what he understands when he says that learners should do something with the input, we believe that this processing could occur, for example, through textual comprehension questions, which would allow learners, after a more general first reading, to return to the text looking for the answers to the questions. This would represent a new opportunity for learners to notice meanings and forms present in the input.

In this sense, although input processing is, in its essence, a technique for explicit instruction, there would be more implicit techniques that could favor input-processing, such as those listed above, or interpretation tasks, according to Vidal (2007), which are designed to "focus learners' attention on a targeted structure in the input and that enable them to identify and comprehend the meaning(s) of this structure." (ELLIS, 1995, p. 88).

If we consider the criteria that help to establish the degree of explicitness of the techniques from Housen and Pierrard's (2005) model, for example, the techniques involved in the treatment of the input described so far cannot be classified as either explicit or implicit.

Therefore, the division into only two terms does not accurately reflect a real scenario. Perhaps for this reason, when developing a taxonomy of form-focused techniques and tasks, of the eleven activities analyzed by Doughty and Williams (1998), only two were considered completely implicit (input flood and task-essential language), based on 
the degree of obstruction of each one. Only one was virtually explicit (garden path), while the others have characteristics that would allow them to be situated along a continuum of more or less implicit activities, as shown in the image below.

Image 1: Degrees of obstruction of form-focused instruction

\begin{tabular}{|c|c|c|c|c|}
\hline & Unobtrusive & & & Obtrusive \\
\hline Input flood & $\mathrm{X}$ & & & \\
\hline Task-essential language & $\mathrm{X}$ & & & \\
\hline Input enhancement & $\mathrm{X}$ & & & \\
\hline Negotiation & $\mathrm{X}$ & & & \\
\hline Recast & & $\mathrm{X}$ & & \\
\hline Output enhancement & & $\mathrm{x}$ & & \\
\hline Interaction enhancement & & $\mathrm{X}$ & & \\
\hline Dictogloss & & & $\mathrm{X}$ & \\
\hline Consciousness-raising tasks & & & $\mathrm{X}$ & \\
\hline Input processing & & & & $\mathrm{X}$ \\
\hline Garden path & & & & $\mathrm{X}$ \\
\hline
\end{tabular}

Source: Doughty and Williams, 1998, p. 258.

In the wake of Doughty and Williams' considerations, we believe that input enhancement, input flood, and input processing techniques would be at different points in the continuum of techniques involving the input. Thus, input enhancement and input flood are non-invasive; they do not include the use of metalanguage and do not allow learners to recognize what they are being taught, and thus, they can be put on the list of the more implicit techniques. However, because input enhancement implicates the manipulation of text from a visual point of view, is less implicit than input flood, since it suggests much more clearly to the learner the linguistic phenomenon that is the target of instruction, i.e., with visualization and written changes, it is as if a flashlight were placed on what is being taught, which shows the learner that didactic techniques are being applied and that a highlighted topic is the target of instruction.

Finally, input processing, in its essence, is a technique closer to the explicit pole, since it involves teacher intervention, requires the learner to manipulate the forms presented to him, deliberately presents the structure and provides the metalinguistic treatment. However, to the extent that learners may be called upon to do "things with the text" (WONG, 2004), there is room for less invasive and, therefore, more implicit techniques to be applied together.

With this, we can think of a spectrum that encompasses the different techniques, which is shown in the figure below:

Figure 1: The implicit-explicit continuum in structured input

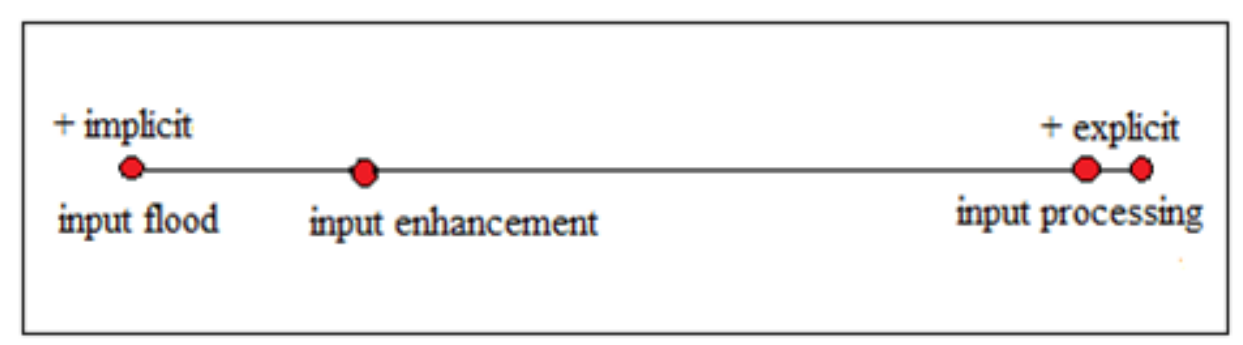

Source: The authors

The update to the concept of explicit and implicit that we propose is not intended to be an exhaustive classification of the techniques that can be applied to the classroom; instead, we simply intend to consider the criteria that define them, to allow the identification of their greater or lesser degree of explicitness concerning what is being taught. The exact definition of their position along the continuum will depend on the numerous variables already discussed above, including the possible adaptations brought by the professor. Thus, the continua we place the techniques in approximate positions, based on their fundamental characteristics.

\section{Instruction combined with a grammatical explanation}


Ellis (1998, p. 47-48) describes that explicit instruction, understood as the moment of grammatical explanation provided by the teacher, essentially involves two choices: "explaining the rules directly", which would constitute a deductive-type technique, or "developing activities that lead the learners to discover the rule autonomously", which would be an inductive-type technique. Both can be accompanied (or not) by grammatical content-fixing exercises in which learners are called upon to test their understanding of the rules presented.

According to the explicit instruction model, PPP, which stands for divided into presentation, practice, and production, the presentation step of the grammatical rule is done in a deductive way, starting from the modeling step, that is, the demonstration of the functioning of the target structure by the teacher (GAUTHIER et al., 2014). At this stage, the teacher, through diversified strategies, introduces the target form of instruction, placing an example taken from the text on the blackboard. The teacher then performs a task in front of his learners and describes step-by-step what he is doing.

After modeling, the teacher begins the next phase: practice, presuming that the repetition of exercises can facilitate the understanding and automation of what is being taught. Right after the modeling step, the learner would not yet have complete confidence to perform the exercises autonomously. Hence, it is up to the teacher to support him and help him learn new notions through guided practice.

After guided practice, the learners would already have developed enough confidence to carry out tasks on their own and, therefore, can move on to independent practice, which only ends when the teacher believes that most of the learners have reached a good number of correct answers. At the end of practice, production takes place when the learner can interact freely with peers or through oral or written tasks planned by the teacher to use the structures practiced in the previous stages.

If in deductive instruction we have this general setting, with the inductive technique to which Ellis (1998) alludes, the teacher, before carrying out the modeling step, offers examples of the form being taught and stimulates the learners to reason and formulate hypotheses on their own about its functioning and function. Usually, the teacher guides the learners in advance through questions that can at least direct the attention and then organizes the work in small groups, individually or by combining, at first, individual work and then group work. Only after the completion of this stage and the discussion of the hypotheses raised by the learners should the teacher move on to the modeling step and then to guided practice, independent practice, and production.

As for the classification of implicit and explicit techniques along the continuum, by comparing the two techniques deductive and inductive grammatical explanation - to the framework provided by Housen and Pierrard (2005), we believe that both direct the learners' attention to the target forms. Therefore, they are invasive; that is, they constitute an interruption of the interaction with a focus on meaning; they expect the use of metalanguage and present the linguistic forms in an isolated way, being, therefore, among the explicit-type instruction techniques. However, the inductive technique tends to be a little less invasive, as it allows the learner to think without the intervention of the teacher, which may indicate that it is slightly less explicit than deductive.

On the opposite end of the continuum, we could frame the III (Illustration-Interaction-Induction) technique created by Carter and McCarthy (1995) as a representative of the implicit perspective. This technique, derived from Corpus Linguistics studies, leads with the Illustration of contents in real corpora. The excerpts contextualize a given structure, whose survey of observations and patterns in FL/L2 may give rise to the second phase of the technique, Interaction, in which learners discuss and exchange impressions about what they have previously observed; thus, learners are given a chance to develop a habit of perceiving consistencies in FL/L2, grasp its key functionalities and use them in the contexts in which they normally occur. The third and final stage of this technique, Induction, requires the teacher to encourage learners to adopt a rule for the target structure, which gets tested with the analysis of more linguistic data. Such a technique encourages learners to research and understand that learning should be autonomous and, at the same time, guided by access to and reflection on real FL data.

These techniques can be distributed along the implicit-explicit continuum as such: 
Figure 2: The implicit-explicit continuum in the grammatical explanation

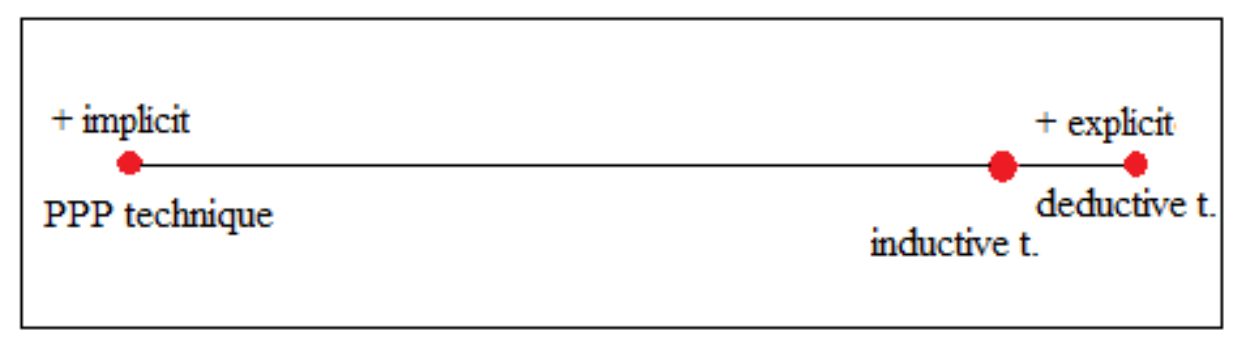

Source: The authors

\section{Instruction combined with opportunities for production of language}

Production of language has gained prominence in the FL/L2 teaching/learning thanks to Merrill Swain's studies on comprehensible output.

First devised in 1985, the concept of comprehensible output came to be because of Swain's belief on the insufficiency of comprehensible input hypothesis, which was considered the only factor capable of triggering acquisition at the time.

In her research, Swain assesses the communicative competence of children in French immersion programs in the city of Toronto, Canada. In the tests carried out, the learners are required to produce texts appropriate to different situations, respecting their degree of formality. In the end, the learners' productions of language are compared to those of native speakers to identify similarities and differences in the grammatical and discursive choices made. From the results found, Swain concludes that the learners' choices, even after seven years of constant contact with authentic input when in immersion in Canada, are significantly different from those present in the texts of native speakers, which leads her to partially refute the hypothesis of the comprehensible input of Krashen (1978).

To rationalize the results, Swain hypothesizes that learners have not sufficiently developed their competence because they had no opportunity to engage in communicative interactions in which the aspects focused on in the tests were required. Thus, she argues that in addition to comprehensible input, learners would need comprehensible output, i.e. "output that extends the linguistic repertoire of the learner as he or she attempts to create precisely and appropriately the meaning desired" (1985, p. 252).

In this perspective, output is not seen merely as the result of the learners' speech or writing, but rather as a process they engage in to make themselves understood by others. In this dynamic, learners are required to reflect on the ways in which they should construct the meaning they wish to convey.

The production of language, as defended by Swain, would then be responsible for promoting many processes, such as noticing, noticing the gap, noticing a hole and hypothesis testing. Noticing (SCHMIDT; FLEET, 1986) is defined as the stage in which the learner consciously notices something new in the target language; this is a crucial moment for the development of communicative competence, since the learner would begin to try to understand the aspect noticed and integrate it progressively into his/her production. Noticing the gap is the idea that the learner, in interactions with native speakers or more competent speakers, can identify that the linguistic form he used differs from the other speaker, making him realize that there is a certain distance between his production and the other speaker's. The third aspect that the learner's output favors, noticing a hole (SWAIN, 1995), concerns his ability to perceive that he cannot formulate in speech or in writing what he would like to express, either because he does not know or because he does not remember how a certain structure is constructed.

Finally, interactions between learners or between the learner and a more competent speaker would play an essential role in making room for the hypothesis test, which would be "from the learner's perspective, a 'trial run' reflecting their hypothesis of how to say (or write) their intent" (SWAIN, 2005, p. 476).

Also, these types of production are deeply connected to the concept of collaborative dialogue. In fact, in a 2000 article, Swain explains that several of her reflections on the relationship between language and thought are based on Vygotsky's statement $(1978,1987)$ that the development of cognitive functions is mediated by language. For Swain, at the moment when the learners' production ceases to have the role of interactive exchange and takes on the function of mediating the construction of knowledge, there is "collaborative dialogue", an expression that will later be replaced by the term languaging (SWAIN, 2006), and exemplified as follows:

when language is used to mediate problem solutions, whether the problem is about which word to use, or how best to structure a sentence so it means what you want it to mean, or how to explain the results of an experiment, or how to make sense of the action of another, or... that languaging occurs. [...] It is the "coming-to-know-while-speaking" phenomenon. That is, while speaking (or writing), we may reach a new or deeper understanding. (SWAIN, 2006, p. 96-97). 
Thus, with Swain and the numerous studies resulting from her reflections, such as Figueiredo (2006), Figueiredo e Assis (2006), Carvalho (2006), among others, the production of learners, previously seen only as a mere practice exercise or as an instrument for increasing fluency, is now playing a much broader and more complex role in language teaching/learning, and is considered one of the central objectives of instruction.

Therefore, instruction, as presented here, should provide moments of significant linguistic production, in which didactic activities are formulated so that learners interact actively and collaboratively with each other in situations that could easily occur outside the classroom, such as in discussions, narratives of experiences, conflict resolution, among others.

According to Vidal (2007), teachers can offer stimuli for written production through text manipulation activities, that is, proposals in which learners fill gaps, order sentences, and complete dialogues to prepare them to produce their text. Thus, the teacher starts from more controlled tasks that directly involve the contents seen in the room and goes towards less controlled ones, such as written production.

The stimulation of oral production can be offered through tasks that require a certain target structure for their success. According to Xavier (2011), this type of technique is called task essentialness. As the author advises, tasks of this kind must be well designed for learners to find communicative strategies that "dribble" the use of the expected structure. If the teacher reveals the necessary structure for the execution, then they use another technique called situational grammar exercise.

Instruction based on oral production can also benefit from communicative practice tasks, defined by Xavier (2011, p. 151) as activities that "presuppose the practice of speech containing the target structure, so that learners can acquire it through its repetition in a communicative context". Unlike task essentialness, with communicative practice tasks, the target structure should not necessarily appear. Thus, this type of activity stimulates communication in a broad sense; encouraged by the desire to carry out a given communicative scope, the learner may feel the need to produce a specific form that they can perceive more easily.

From the point of view of the explicitness of the activities, text manipulation tasks, e.g., filling up passages with structures seen in class, as well as situational grammar exercises, are considered activities that are near the explicit end, since the learner is aware of what is being required. On the other hand, communicative practice tasks and tasks with essential use of the target structure are more implicit in nature, as the learner is unaware of the language structures that constitute the focus of the tasks (Figure 3).

Figure 3: The implicit-explicit continuum and production of language activities

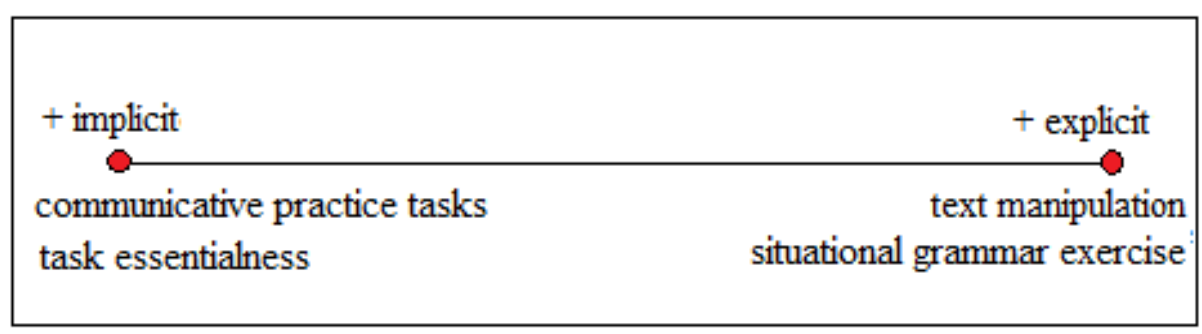

Source: The authors

In Figure 3, the techniques cited in this section were placed at both ends, since it was not possible to identify the exact degree of explicitness of each one. Therefore, the techniques were classified as "more" implicit or "more" explicit. Other studies have tried to create mechanisms to measure how much a given activity can be considered explicit/implicit (SANCHEZ et al., 2010; DOUGHTY; WILLIAMS, 1998), but this was not our objective here.

\section{Instruction combined with corrective feedback}

According to Lyster and Ranta (1997, p. 38), the name of a speaker's reaction to mistakes in the production of FL/L2 learners depends mainly on the perspective of the observer of interaction. If the observer follows the field of linguistics research, the reaction to mistakes is called negative evidence; if he follows the domain of discourse analysis, it is called repair. In psychology, it is called negative feedback, while in the area of language teaching/learning, it is called corrective feedback.

Aside from the more superficial differences linked to nomenclature, the way of seeing the mistake and the function of correction change considerably according to the beliefs and goals of each researcher.

In an attempt to make an inventory of the techniques used in the classroom to correct mistakes, Lyster and Ranta (1997) observed six groups of learners learning French as a L2 and analyzed the oral interactions between them and their teachers. 
As a result of the analyses, the researchers identified six techniques most commonly used by teachers: 1 . explicit correction; 2. recasts (or requests for rephrasing); 3. clarification requests; 4. metalinguistic feedback; 5. elicitation of form; and 6. repetition.

In explicit correction, the teacher offers the correct form in place of the form used by the learner through expressions like "You meant...", "The correct term would be...".

In recasts or rephrasings, these expressions are not used, and feedback is offered as a paraphrase of the statement made by the learner, excluding the mistake, and inserting the correct form. The teacher can rephrase all or part of the learner's sentence, including using the translation into the learner's L1, in an apparent effort to make him understand what he did wrong without explicitly saying it.

With clarification requests, teachers expect that learners find the mistake and recast it. This is done by indicating that they have not understood the statement or that it is not well constructed. Requests for clarification are expressed with sentences like "I'm sorry, I didn't understand", "How?", "What did you mean by...?".

Metalinguistic feedback is built on comments that explain the rule behind the form, without providing the correct form. With this strategy, the teacher tries to remind the learner of the rule that he came into contact with before, making him reconstruct his statement. Usually, this kind of feedback is accompanied by metalinguistic references, such as "this word is masculine", "the subject of the sentence is plural", among others.

The elicitation of form refers to the partial repetition of the learner's statement with a pause before the mistake, that is, the teacher intentionally creates a gap in the sentence and asks the learner to complete it, drawing his attention to the fact that he has made a mistake precisely in the missing part.

Finally, the repetition technique is based on the isolation of the mistake made by the learner and its repetition by the teacher. In some cases, repetition may occur with an interrogative intonation so that the learner realizes that the repetition is in fact a request for rewording, not agreement with what he has just said.

In addition to these techniques, our experience in the classroom and the observation of the practice of FL allow us to defend that, in the case of written productions, there is another technique: the creation of symbols indicating the type of mistake made. For example, one can adopt "MM" as an acronym for morphosyntactic mistakes, "Sp" for spelling mistakes, "L" for lexicon, among others. Taking into account Lyster and Ranta's typologies, we believe that this type of reaction to the mistake can fit into the metalinguistic feedback technique, since it indicates the scope to which the mistake is linked, but does not provide the correct form.

Although the authors have dwelt only on the type of feedback provided by teachers, in an environment where work in pairs and groups is encouraged, it is to be expected that the learners themselves will also provide corrective feedback. Thus, during the activities, learners can notice the mistakes in their peers' productions (oral and written) and try to help them. In this way, besides the teacher, learners can also perform the techniques listed above.

As is the case of other types of FL/L2 teaching techniques and instruction from corrective feedback, it is possible to place them along the implicit-explicit continuum (Figure 4). More implicit techniques, such as recast, clarification request, elicitation, repetition and rephrasing, the teacher does not consider the form from a metalinguistic point of view, and the learner is not informed if and in about what exactly they made a mistake. More explicit techniques, such as explicit correction and metalinguistic feedback, through which the learner identifies exactly the linguistic element that they have not been able to use properly. Again, as in Figure 3, because we cannot identify the exact degree of explicitness, we have chosen to place them at the ends of the continuum.

Figure 4: The implicit-explicit continuum and types of corrective feedback

\begin{tabular}{|lr|}
\hline+ implicit & + explicit \\
recasts & explicit correction \\
clarification requests & metalinguistic feedback \\
elicitation & \\
repetition & \\
\hline
\end{tabular}

Source: The authors

Now that we have addressed the four moments on which instruction can be based, we must mention the impossibility of speaking of explicit and implicit instruction from a general point of view, without considering the techniques that will be implemented in the classroom. In scientific research, where methodologies are described in detail, the terms used must be defined in such a way as to avoid misunderstandings and ambiguities. 
Thus, when we speak of explicit instruction or implicit instruction, we are referring to a set of practices selected by the teacher or researcher, and not just restricting ourselves to the type of explanation of linguistic phenomena provided to learners.

\section{Final remarks}

In this study, we traced a path that started from the broadest concept of instruction to arrive at the classification of pedagogical techniques along an implicit-explicit continuит.

First, we showed how dichotomies are fundamental constructions for the field of linguistics in general and, more specifically, for the area of language teaching/learning. We then focused on the concept of instruction, and its definition as the adoption of pedagogical mechanisms aimed at intervention in learning. We presented the three fundamental factors in this process: what is taught, who is taught, and how instruction occurs.

From the multiple options available regarding how to teach something, we reflected on how the implicit and explicit binomial has been treated in scientific research since the 1990s. We also saw how, in some of these studies, there is a lack of detail in the practical procedures adopted to operationalize the theoretical concept.

Finally, based on Housen and Pierrard (2005), who address factors focused on the teaching activity to differentiate the two types of instruction, we formulated four continua based on the four moments in which instruction can intervene: the presentation of the input, the grammatical explanation, the activities of output stimulation and corrective feedback. Thus, we considered that, for each of these four moments, one should think about the degree of explicitness of the techniques adopted, using as reference the continuum provided for that didactic stage.

From a practical point of view, this means that for a given study to investigate the effects of explicit instruction, the instruction must tackle only or predominantly explicit techniques, i.e., located at the end of the continuum. On the other hand, implicit studies should privilege techniques placed on the implicit end of the continuum. If, in the same study, the authors adopt implicit techniques in some moments and explicit ones in others, then it would be essential to problematize this situation and to take into account this configuration in the analysis of the results.

Through our proposal, we hope that future studies clarify how classroom instruction is delineated and how it operates in its four central moments. Thus, we hope that our article adds to how this continuum is being recognized and its effects on learning.

\section{References}

Andrews, K. L. Z. (2007). The effects of implicit and explicit instruction on simple and complex grammatical structures for adult English language. TESL-EJ, 11(2), 1-13.

Bongaerts, T. (1999). Ultimate attainment in L2 pronunciation: the case of very advanced late L2 learners. In D. Birdsong (ed.). Second language acquisition and the critical period hypothesis. (pp. 133-159). Mahwah: Lawrence Erlbaum Associates.

Bortoni-Ricardo, S. M. (2004). Educação em língua materna: a sociolinguística na sala de aula. São Paulo: Parábola, 2004.

Carter, R., \& Mccarthy, M. J. (1995). Grammar and the spoken language. Applied Linguistics, 16(2), 141158.https://doi.org/10.1093/applin/16.2.141

Carvalho, G. O. (2006). Os efeitos da revisão colaborativa em textos escritos em língua inglesa por alunos iniciantes do curso de Letras. In F. J. Q. Figueiredo (ed.). A aprendizagem colaborativa de línguas. (pp. 201-230). Goiânia: Ed. da UFG.

Chomsky, N. (1965). Aspects of the theory of sintax. Massachusetts: The Massachusetts Institute of Technology.

Dekeyser, R. (2003). Implicit and explicit learning. In: C. Doughty; M. Long (eds.). Handbook of second language acquisition. (Cap. 11, pp. 313-349). Malden: Blackwell.https://doi.org/10.1002/9780470756492.ch11

Doughty, C.; \& Williams, J. (1998). Focus on form in classroom second language acquisition.Cambridge: Cambridge University Press.

Ellis, R. (1995). Interpretation tasks for grammar teaching. Tesol Quarterly, 29(1), 87-105. https://doi.org/10.2307/3587806

Ellis, R. (1998) Teaching and research: options in grammar teaching. Tesol Quarterly, 32(1), 39-60. https://doi.org/10.2307/3587901

Ellis, R. (2009). Implicit and explicit learning, knowledge and instruction. In R. ELLIS; S. LOEWEN; C. ELDER; R. ERLAM; J. PHILIP; \& H. REINDERS (eds.). Implicit and explicit knowledge in second language learning, testing and teaching (pp. 3-25). Bristol, Buffalo, Toronto: Multilingual Matters. https://doi.org/10.21832/9781847691767-003

Figueiredo, F. J. Q. (ed.) (2006). A aprendizagem colaborativa de línguas. Goiânia: Ed. da UFG.

Figueiredo, F. J. Q.; \& Assis, N. (2006). A auto-estima e a atitude quanto à escrita na revisão colaborativa. In F. FIGUEIREDO (ed.). A aprendizagem colaborativa de línguas (pp. 165-199). Goiânia: Ed. da UFG.

Author (2019).

36 
Author (2014).

Gauthier, C.; Bissonnette, S.; \& Richard, M. (2014). Ensino explícito e desempenho dos alunos: a gestão dos aprendizados. (S. Matousek, Trans). Petrópolis: Vozes.

Harley, B. (1993). Instructional strategies and second language acquisition in early French immersion. Studies in Second Language Acquisition, 15, 245-259.https://doi.org/10.1017/S0272263100011980

Housen, A.; \& Pierrard, M. (eds.) (2005). Investigations in instructed second language acquisition. Berlin, New York: Mouton de Gruyter.

Hymes, D. H. (1962). The ethnography of speaking. In T. Gladwin; W. Sturtevant (eds.). Anthropology and human behavior (pp. 13-53). Washington: American Anthropology Association.

Hymes, D. H. (1966). On communicative competence. Proceedings of the Research planning conference on language development in disadvantaged children (pp. 1-23). New York: Yeshiva University.

Hymes, D. H. (1972). On communicative competence. In J. B. Pride; J. Holmes (eds.). Sociolinguistics:selected readings (pp. 269-293). Harmondsworth: Penguin.

Krashen, S. D. (1978). Individual variation in the use of the monitor. In W. Ritchie (ed.). Principles of Second Language Learning (pp. 175-183).New York: Academic Press.

Krashen, S. D. (1982). Principles and practice in second language acquisition. London: Pergamon.

Krashen, S. D. (1985). The input hypothesis: issues and implications (4. Ed). New York: Longman.

Long, M.; \& Robinson, P. (1998). Focus on form: theory, research and practice. In C. Doughty; J. Williams (eds.). Focus on form in second language acquisition (pp. 15-41).Cambridge: Cambridge University Press.

Lyster, R. (1994). The effect of functional-analytic teaching on aspects of French immersion students. Applied Linguistics, 15(3) 263-287.

Lyster, R.; \& Ranta, L. (1997). Corrective feedback and learner uptake: negotiation of form in communicative classrooms. Studies in Second Language Acquisition, 20, 37-66. https://doi.org/10.1017/S0272263197001034

Moskver, K. (2008). Register and genre in course design for advanced learners of Russian. Foreign Language Annals, 41(1), 119-131. https://doi.org/10.1111/j.1944-9720.2008.tb03282.x

Neupane, M. (2009). Processing instruction: an input based approach for teaching grammar. Journal of Nelta. 14(1), 111-118.https://doi.org/10.3126/nelta.v14i1.3097

Norris, J; \& Ortega, L. (2000). Effectiveness of L2 instruction: a research synthesis and quantitative meta-analysis. Language Learning, 50, 417-528. https://doi.org/10.1111/0023-8333.00136

Sanchez. R.; Perez, A. S.; \& Gomez, P. C. (2010). An attempt to elaborate a construct to measure the degree of explicitness and implicitness in ELT material.International Journal of English Studies, 10(1), 103129.https://doi.org/10.6018/ijes/2010/1/114001

Saugera, V. (2011). Scriptwriting as a tool for learning stylistic variation. Foreign Language Annals, 44(1), 137152.https://doi.org/10.1111/j.1944-9720.2010.01122.x

Saussure, F. (2000). Curso de Linguística Geral (22. ed.). São Paulo: Cultrix.

Schmidt, R. (1990). The role of consciousness in second language learning. Applied Linguistics, 11(2), 129158.https://doi.org/10.1093/applin/11.2.129

Schmidt, R.; \& Frota, S. (1986). Developing basic conversational ability in a second language: a case study of an adult learner of Portuguese. In R. Day (ed.). Talking to learn: conversation in second language acquisition (pp. 237-326). Rowley: Newbury House.

Spada, N. (2011). Beyond form-focused instruction: reflections on past, present and future research. Language Teaching,44(2), 225-236. https://doi.org/10.1017/S0261444810000224

Swain, M. (1985). Communicative competence: some roles of comprehensible input and comprehensible output in its development. In S. Gass; \& C. Madden (eds.). Input in Second Language Acquisition (pp. 235-253). Cambridge: Newbury House.

Swain, M. (1995). Three functions of output in second language learning. In G. Cook; B. Seidlhofer, B. (org.). Principle and Practice in Applied Linguistics (pp. 125-144). Oxford: Oxford University Press.

Swain, M. (2005). The output hypothesis: theory and research. In E. Hindel (ed.). Handbook of Research in Second Language Teaching and Learning (pp. 471-483). Yahweh: Lawrency Erlbaum Associates. https://doi.org/10.4324/9781410612700

Swain, M. (2006). Languaging, agency and collaboration in advanced second language learning. In H. Byrnes (ed.). Advanced Language Learning: the contributions of Halliday and Vygotsky (pp. 95-108).London, New York: Continuum.

VanPatten, B. (2002). Processing instruction: an update. Language Learning, 52(4), 755-803. https://doi.org/10.1111/1467-9922.00203

VanPatten, B; Oikkenon, S. (1996). Explanation versus structured input in processing instruction. Studies in Second Language Acquisition, 18(4), 495-510. https://doi.org/10.1017/S0272263100015394 
Vidal, R. (2007). Ensino-aprendizagem do foco na forma: retorno ou recomeço? TheEspecialist, 28(2), $159-184$.

Vygotsky, L. (1978). Mind in society: the development of higher psychological processes. Cambridge: Harvard University Press.

Vygotsky, L. (1987). The collected works of Lev. S. Vygotsky: problems of general psychology. New York: Plenum Press.

Xavier, R. P. (2011). Metodologia do ensino de inglês. Florianópolis: LLE/CCE/UFSC.

Wong, W. (2004). The nature of processing instruction. In VanPatten, B. (ed.). Processing instruction:theory, research, and commentary (pp. 33-63). Mahwah: Lawrence Erlbaum. 